\title{
Atmospheric Instability Conditions during Rainy Seasons over Tanzania
}

\author{
Pasvolo J Mwinuka ${ }^{1,4 *}$, Christian BS Uiso ${ }^{2}$, Ladslaus B Chang'a ${ }^{3}$ and Mwingereza J \\ Kumwenda $^{4}$ \\ ${ }^{\text {I} P h y s i c a l ~ S c i e n c e s ~ D e p a r t m e n t, ~ O p e n ~ U n i v e r s i t y ~ o f ~ T a n z a n i a, ~ P . O . ~ B o x ~ 23409, ~ D a r ~ e s ~ S a l a a m, ~}$ \\ Tanzania.Email: mwinuka.pasvolo@gmail.com \\ ${ }^{2}$ Marian University College, P.O. Box 47 Bagamoyo, Tanzania. \\ Email: cbsuiso2010@gmail.com \\ ${ }^{3}$ Tanzania Meteorological Authority, Dar es Salaam, Tanzania. \\ Email: changa607@gmail.com \\ ${ }^{4}$ Department of Physics, University of Dar es Salaam, P.O. Box 35063, Dar es Salaam, \\ Tanzania. Email: kmwingereza@yahoo.com \\ *Corresponding author
}

Received 27 May 2021, Revised 13 Oct 2021, Accepted 25 Oct 2021, Published Dec 2021

DOI: https://dx.doi.org/10.4314/tjs.v47i5.14

\begin{abstract}
The amount of rainfall and its distribution in time and space is dependent on the atmospheric instability conditions, and on its moisture content. The aim of this study was to determine the atmospheric instability conditions during January to March (JFM), February to April (FMA), March to May (MAM), and October to December (OND) rainy seasons over local climate zones in Tanzania. Zone area average seasonal Convective Available Potential Energy (CAPE), Convective Inhibition (CIN), Precipitable Water (PW) and Lifted index (Li) were calculated and analyzed. Results showed Li $<0$ in JFM and FMA over whole Tanzania. During MAM and OND, $\mathrm{Li}<0$ over the Lake Zone, Western Highlands Zone and Central Zone only. CAPE ranged from $793 \mathrm{~J} / \mathrm{kg}$ to $1183 \mathrm{~J} / \mathrm{kg}$ during JFM, and $700 \mathrm{~J} / \mathrm{kg}$ to $1080 \mathrm{~J} / \mathrm{kg}$ during FMA. During MAM, CAPE ranged from $170 \mathrm{~J} / \mathrm{kg}$ to $921 \mathrm{~J} / \mathrm{kg}$ and from $173 \mathrm{~J} / \mathrm{kg}$ to $833 \mathrm{~J} / \mathrm{kg}$ during OND. Results also showed CAPE > $1000 \mathrm{~J} / \mathrm{kg}$ over the Lake Zone, Western Highlands Zone, Island Zone, and Central Zone. These results show that the atmosphere was moderately unstable during the JFM and FMA and was weakly unstable during the MAM and OND. Therefore, the atmosphere is likely to be more convective during JFM and FMA seasons.
\end{abstract}

Keywords: Lifted index, Convective inhibition, Precipitable water, Convective available potential energy, Atmospheric instability.

\section{Introduction}

Local rainfall cycles and trends are dependent on three moisture sources: The moisture present in the atmosphere, the moisture transported into the region by winds, and recycling. The first source has little contribution, and therefore, the major sources are the last two which are related to baroclinic and atmospheric convective instability, respectively (Nieto et al. 2010). Atmospheric instability condition during the rainy seasons is important as it determines the intensity of rainfall. Understanding the status of the atmosphere helps to determine the nature of rain that is going to fall. In the tropical regions, one of the factors that influence the occurrence and intensity of rainfall is atmospheric convection and circulation (Davies et al. 2013, Lepore et al. 2014).

Atmospheric instability is related to Convective Available Potential Energy $(C A P E)$, Convective Inhibition $(C I N)$ and 
Precipitable Water $(P W)$ (Myoung and Nielsen-Gammon 2010). CAPE describes the amount of energy for convection; it is the maximum kinetic energy per unit mass that would be attained by an ideal and undiluted ascending air parcel (Myoung and NielsenGammon 2010). CAPE is given by the vertical integral of the buoyancy of the parcel integrated from the level of free convection $(L F C)$ to the level of zero buoyancy $(N)$ (Holley et al. 2014). It is applied in the forecasting of severe weather and rainfall (Lepore et al. 2014). CIN is the measure of how much energy is hindering the occurrence of convection (Rasmussen et al. 2020). In other words, CIN is a measure of the amount of energy that is sufficiently enough for initializing convection; large values of CIN prevent convection from initializing (Keil et al. 2014). The significance of CIN in modifying convective rainfall lies in the fact that a rising air parcel will not reach the $L F C$ unless it overcomes any $C I N$ preventing it. The magnitude of $C I N$ is the amount of energy that should be given to the rising air parcel for it to reach the level of free convection (LFC) (Yin et al. 2015), more negative $C I N$ represents more energy that must be overcome by a rising air parcel. Convection will not occur even if there exists a large $C A P E$ in the presence of large values of $C I N . P W$ is defined as the total vertical column of the atmospheric water vapour from the surface to the top of atmosphere (Liu et al. 2019). The top of atmosphere here means the pressure level beyond which atmospheric moisture is negligible (Zhao et al. 2020). $P W$ is important for atmospheric stability as it is involved in convective processes and in moisture transport resulting from unequal heating of the atmosphere by latent heat energy released during phase transitions (Liu et al. 2019).

Another common measure of the atmospheric convective instability in the tropics is the Lifted Index ( $\mathrm{Li}$ ) (DeRubertis 2006). $L i$ is defined as the temperature difference between the environment and an adiabatically lifted air parcel at $500 \mathrm{hPa}$. The air parcel is lifted dry adiabatically from the surface to the Lifting Condensation Level
( $L C L)$ and then it is lifted further to the 500 $\mathrm{hPa}$ level by following the moist adiabat. Values of the $L i$ less than zero indicate unstable atmosphere and values greater than zero indicate stable atmosphere. It is a measure of atmospheric instability; more negative values mean more unstable atmosphere (DeRubertis 2006).

Changes in the parameters defining baroclinic and convective instabilities affect rainfall distribution by altering its predictability. Amount of rainfall that is going to fall depends on the atmospheric instabilities (Trenberth et al. 2003). Also, rainfall is proportional to the condensation and to the atmospheric convective systems (Sui et al. 2007). This research paper was motivated by a study by Mwinuka et al. (2021) on the seasonal rainfall predictability, whose results showed that rainfall predictability has a west-east gradient and that rainfall in January to March (JFM) and February to April (FMA) is more reliable than in March to May (MAM) and October to December (OND), as it was found to have high predictability due to constancy in the rate of variability. The western part showed higher predictability due to constancy in the rate of variability, while the eastern part showed higher predictability due to seasonality. MAM and OND were found to have high predictability due to constancy in the eastern part of Tanzania (Mwinuka et al. 2021).

One of the factors that influence the occurrence and distribution of rainfall in the tropics is the atmospheric instability condition (Davies et al. 2013). In Nigeria, it has been found that the seasonal variability patterns of the atmospheric instability parameters and rainfall are similar (Matthew et al. 2021). Also, in the tropics, much of the urban heavy rainfall events are enhanced by the organized convection in the lower troposphere, and the atmospheric thermodynamic indices (atmospheric instability indices) which depend on temperature and/or dew point temperature at specific geopotential height levels are important in the determination of such organized convections (Ajilesh et al. 2020). Therefore, determining the 
atmospheric instability conditions during the rainy seasons in Tanzania is important for the understanding of the seasonal rainfall predictability as determined by Mwinuka et al. (2021). Hence, the objective of the current study was to determine the atmospheric instability conditions during JFM, FMA, MAM and OND rainfall seasons over Tanzania which might have influenced the observed rainfall predictability results as presented in Mwinuka et al. (2021), by analyzing the CAPE, CIN, PW and the lifted index $(\mathrm{Li})$ over the local climate zones of Tanzania.

\section{Materials and Methods}

The study area is Tanzania, and data analysis was performed in each of the climate zones shown in Figure 1.
Geopotential $(\Phi)$, upper air temperature $(T)$ and upper air relative humidity $(R H)$ data from $1000 \mathrm{hPa}$ to $200 \mathrm{hPa}$ levels and 2-m surface air temperature $\left(T_{2 m}\right)$ zone area average monthly data was obtained from the ECMWF Re-Analysis 5 (ERA5) (Hersbach et al. 2020). The $\Phi$ was used to calculate the geopotential height $(Z)$ by dividing $\Phi$ by the standard gravity $\left(9.80665 \mathrm{~m} / \mathrm{s}^{2}\right)$. Then, corresponding to each $\mathrm{Z}$, the air pressure $(P)$ from $1000 \mathrm{hPa}$ to $200 \mathrm{hPa}$ pressure levels were calculated by using the barometric formula (Berberan-Santos et al. 1997) and hypsometric equation (Trier et al. 2004). The hypsometric equation gave air pressure close to the given pressure level from $1000 \mathrm{hPa}$ to $600 \mathrm{hPa}$, while the barometric formula gave air pressure close to the given level for the levels from $550 \mathrm{hPa}$ to $200 \mathrm{hPa}$.

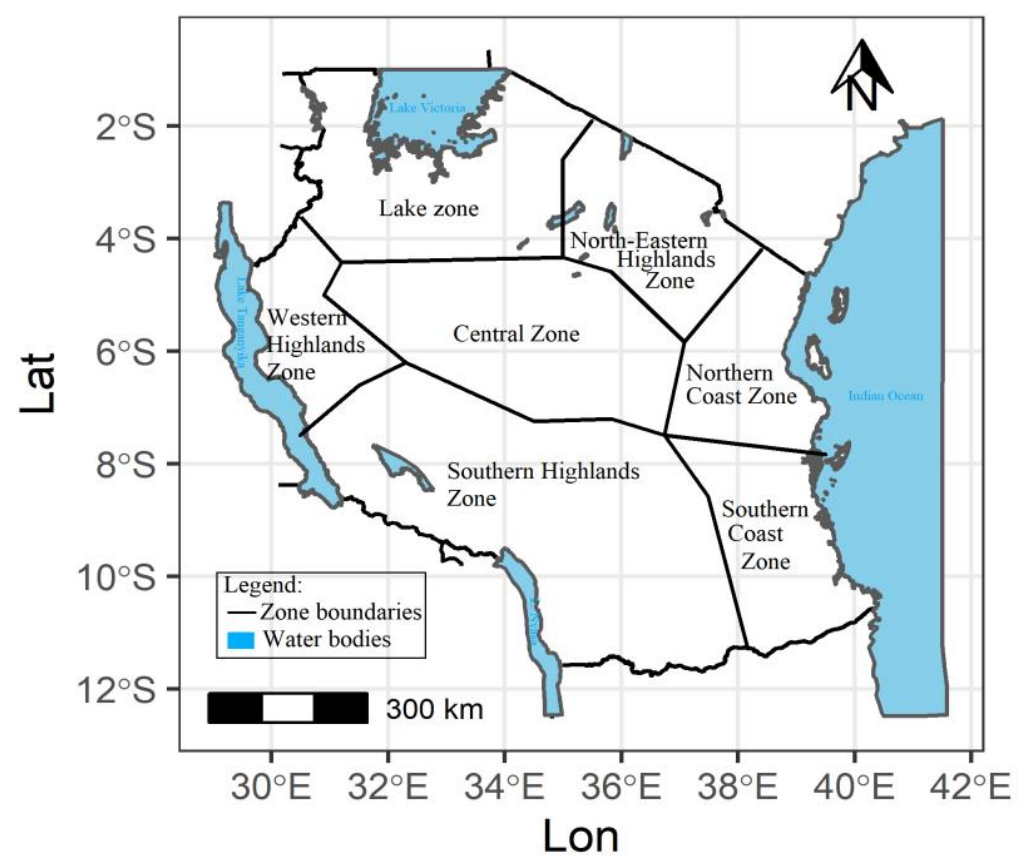

Figure 1: Map of Tanzania showing the local climate zones (Mwinuka et al. 2021).

Then, $P, T, R H$ and $T_{2 m}$ were used in the calculation of convective instability parameters (CAPE, CIN, $P W$ and $L i$ ). In the calculation of $C A P E$ and $C I N$, the air parcel was released from the surface, and calculation proceeded up to $200 \mathrm{hPa}$ level. CAPE and $C I N$ were calculated as in Holley et al. (2014):

$$
C A P E=\int_{L F C}^{E L} R_{d}\left[T_{v p}-T_{v e}\right] d \ln p
$$


and,

$$
C I N=\int_{s f c}^{L F C} R_{d}\left[T_{v e}-T_{v p}\right] d \ln p
$$

where in Equations (1) and (2), $R_{\mathrm{d}}$ is the dry air gas constant, $P$ is pressure, $E L$ is the equilibrium level, $T_{\mathrm{vp}}$ is parcel temperature, and $T_{\mathrm{ve}}$ is the environmental virtual temperature.

The $P W$ was obtained by integrating vertically from pressure $P_{1}$ to $P_{2}$ as in (Liu et al. 2013):

$$
P W=\frac{0.622}{g} \int_{P_{1}}^{P_{2}}\left(\frac{e}{P-e}\right) d P
$$

where in Equation (3), $e$ is vapour pressure, $P_{1}$ is the calculated surface pressure $(\mathrm{Pa}), P_{2}$ is the calculated air pressure $(\mathrm{Pa})$ at $200 \mathrm{hPa}$ level, air pressure at this level is set as the upper limit of integration in Equation (3) because beyond about this value the atmospheric moisture is negligible (Zhao et al. 2020), and $g$ is the acceleration due to gravity $\left(\mathrm{m} / \mathrm{s}^{2}\right)$. The lifted index ( $\left.\mathrm{Li}\right)$ (DeRubertis 2006) was calculated by subtracting the air parcel temperature from the environmental temperature at $500 \mathrm{hPa}$ level, as in Equation (4),

$$
L i=T_{500 h P a}-T_{\text {parcel.500hPa }}
$$

where $T=$ environmental (ambient) temperature and $T_{\text {parcel }}$ is the parcel temperature at the $500 \mathrm{hPa}$ level.

All calculations were done using $R$ software (R Core Team 2020) and aiRthermo $R$ package (Sáenz et al. 2018).

The interpretation of calculated CAPE was based on: $C A P E<1000 \mathrm{~J} / \mathrm{kg}$, weakly unstable; $1000-2500 \mathrm{~J} / \mathrm{kg}$, moderately unstable; and $2500-4000 \mathrm{~J} / \mathrm{kg}$, unstable or strong instability (Yin et al. 2015). The interpretation of $L i$ was based on: $L i$ of 0 to 3, Stable; $L i$ from 0 to -3 , marginally unstable; $\mathrm{Li}$ from -3 to -6 , moderately unstable; and $L i$ from - 6 to -9 , highly unstable (DeRubertis 2006). The interpretation of CIN was based on Rasmussen et al. (2020), where $C I N<-50$ $\mathrm{J} / \mathrm{kg}$ (weak inhibition), $-50 \mathrm{~J} / \mathrm{kg}>C I N>-200$ $\mathrm{J} / \mathrm{kg}$ (moderate inhibition) and CIN $<-200$ $\mathrm{J} / \mathrm{kg}$ (strong inhibition).

\section{Results}

The results presented in Figure 2 show the distribution of convective available potential energy (CAPE), convection inhibition $(C I N)$, lifted index $(\mathrm{Li})$ and precipitable water $(P W)$ in the local climate zones of Tanzania during the JFM season. In Figure 2a, the CAPE $>1000 \mathrm{~J} / \mathrm{kg}$ in the Islands, South coast, Lake and Western highlands zones which indicates moderate instability of the atmosphere, the remaining zones have $C A P E$ between about $793 \mathrm{~J} / \mathrm{kg}$ and $964 \mathrm{~J} / \mathrm{kg}$. In Figure $2 \mathrm{~b}, C I N \geq-$ $50 \mathrm{~J} / \mathrm{kg}$ in all zones except in the Northeastern highlands where $C I N<-50 \mathrm{~J} / \mathrm{kg}$. Since $C A P E$ is high and the $C I N$ is low $(|C I N|<50 \mathrm{~J} / \mathrm{kg})$, the atmosphere was weakly to moderately convective during the JFM season. The $L i$ shows that the atmosphere is marginally unstable in all zones during the JFM season since $L i$ (Figure 2c) is between 0 and $-3{ }^{\circ} \mathrm{C}$. The atmospheric convection in the eastern zones, specifically in the Islands, Northern coast and Southern coast zones is enhanced by high $P W(>40 \mathrm{~mm})$, whereas in the Western zones, Central, Lake and Northeastern highlands zones, the $P W$ has values ranging from $32 \mathrm{~mm}$ to $37 \mathrm{~mm}$ (Figure $2 \mathrm{~d}) . P W$ has an east-west gradient; this is due to the presence of the Indian Ocean in the eastern part because the amounts and concentrations of $P W$ are affected by atmospheric moisture transport, mainly from Oceanic sources and evaporation from local sources such as rivers and forests (Ryu et al. 2015). 


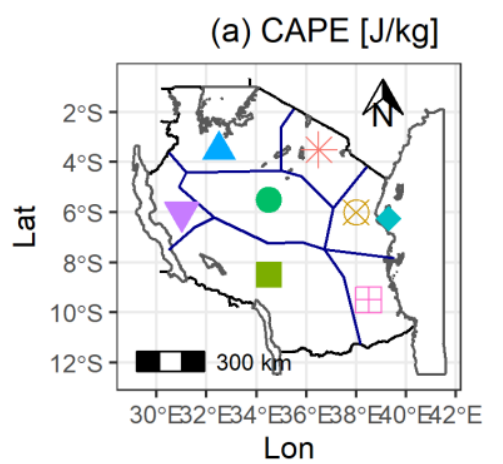

CAPE

* 793

$\varnothing 950$

963

- 964

> 1073

- 1125

$\checkmark 1142$

1163

Lon

(c) Li [deg C]

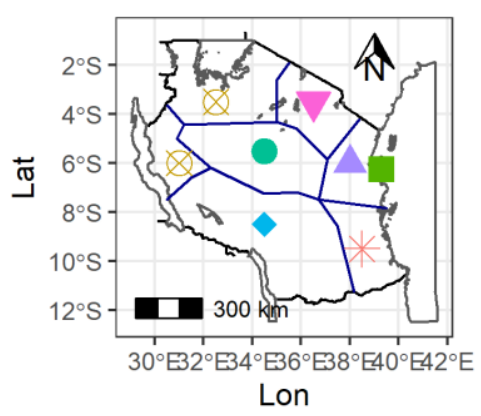

(b) $\mathrm{CIN}[\mathrm{J} / \mathrm{kg}]$

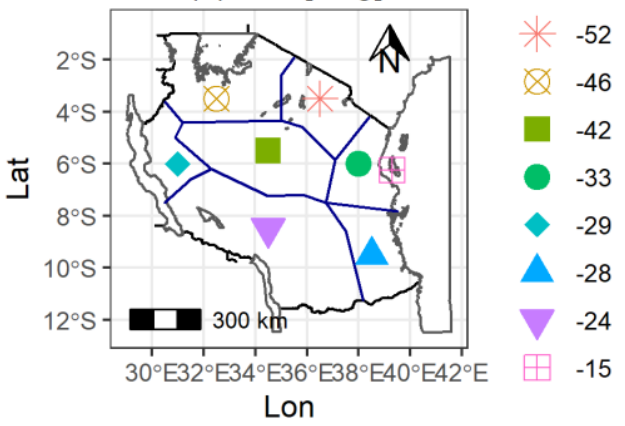

(d) PW [mm]

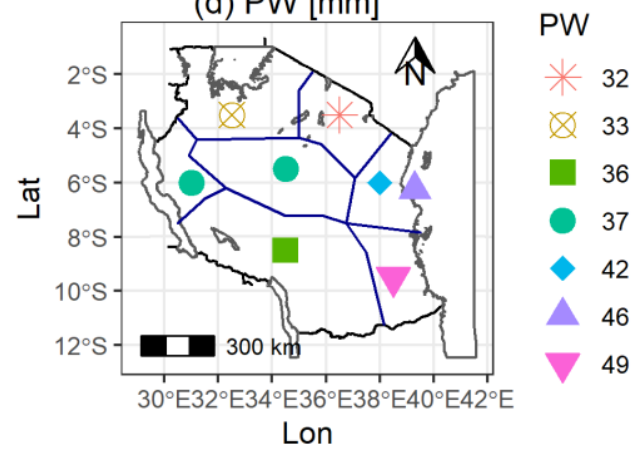

Figure 2: Average variations of the instability parameters during the JFM season in Tanzania.

During the FMA season (Figure 3) the atmosphere is characterized by high $C A P E$ $(>1000 \mathrm{~J} / \mathrm{kg})$ in the eastern and western zones, specifically over the Islands, Southern coast, Lake and Western highlands zones (Figure 3a). The remaining zones, namely, the Central, Southern Highlands, Northern coast and the Northeastern Highlands zones have $C A P E$ values ranging from $713 \mathrm{~J} / \mathrm{kg}$ to 899 $\mathrm{J} / \mathrm{kg}$. The $C I N$ (Figure $3 \mathrm{~b}$ ) has values larger than $-50 \mathrm{~J} / \mathrm{kg}$ over all the zones: this is a low inhibition energy which can be easily overcome by a rising air parcel and manage to reach the level of free convection $(L F C)$. The lifted index (Figure $3 \mathrm{c}$ ), $L i$ has values ranging from $-0.31{ }^{\circ} \mathrm{C}$ to $-1.1{ }^{\circ} \mathrm{C}$, which indicates a marginally unstable atmosphere. Again, as it was for the JFM season, the convection in the atmosphere over the eastern coast zones (Islands, Northern coast, and the Southern coast zones) is enhanced by high $P W$ ranging from $43 \mathrm{~mm}$ to $48 \mathrm{~mm}$ (Figure $3 \mathrm{~d}$ ). 
(a) CAPE [J/kg]

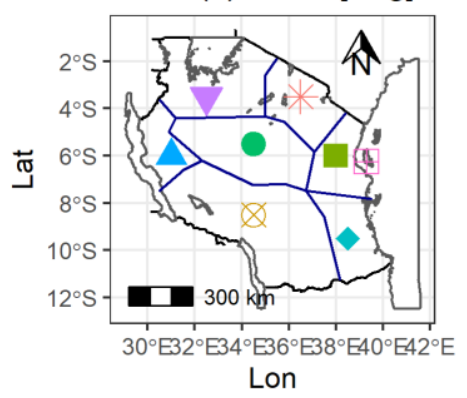

(c) Li [deg C]

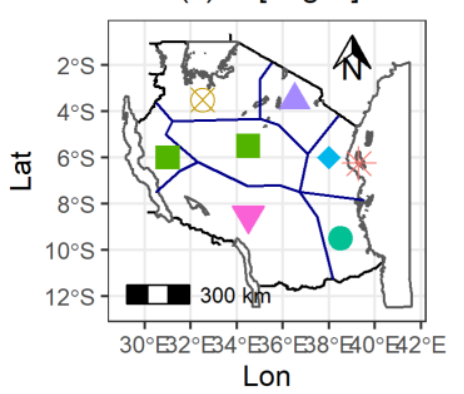

CAPE

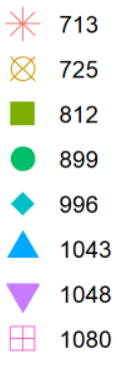

$\mathrm{Li}$

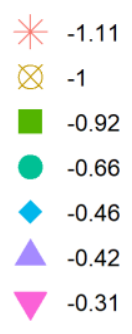

Figure 3: Average variations of the instability parameters during the FMA season in Tanzania.

During MAM season, the CAPE had a range from $170 \mathrm{~J} / \mathrm{kg}$ to $921 \mathrm{~J} / \mathrm{kg}$ (Figure $4 \mathrm{a}$ ) which is lower than that of JFM and FMA seasons. The CAPE is relatively high in the Islands Zone $(C A P E=921 \mathrm{~J} / \mathrm{kg})$, in the Lake Zone $(C A P E=788 \mathrm{~J} / \mathrm{kg})$ and in the Western Highlands Zone $(C A P E=688 \mathrm{~J} / \mathrm{kg})$ and the lowest $C A P E$ is in the Southern Highlands Zone $(C A P E=170 \mathrm{~J} / \mathrm{kg})$. These results indicate that during the MAM season the atmosphere is less convective than during the JFM and FMA seasons. CIN values (Figure $4 \mathrm{~b}$ ) ranged from $-4 \mathrm{~J} / \mathrm{kg}$ to $-77 \mathrm{~J} / \mathrm{kg}$ indicating a moderate inhibition, which is a higher inhibition as compared to the values of CIN observed during JFM (Figure 2b) and FMA (Figure $3 b$ ) seasons. The Lifted index (Figure $4 c)$ values show that the atmosphere is stable

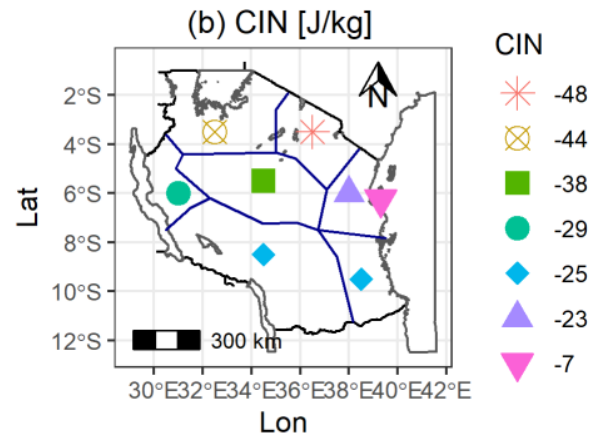

(d) PW [mm]

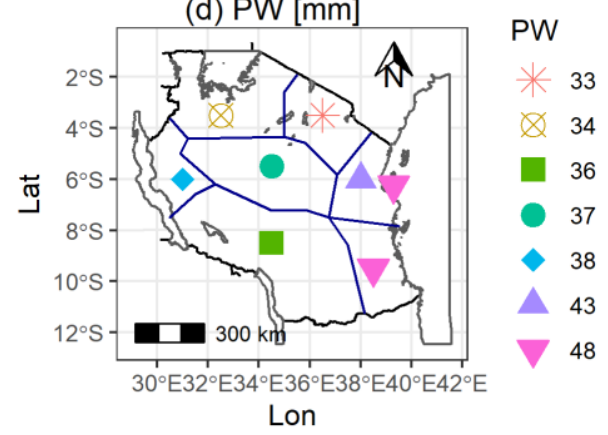

during the MAM season over the Southern Highlands Zone, Southern coast zone, Northern coast zone and over the Northeastern highlands zone where $L i>0{ }^{\circ} \mathrm{C}$, and $L i<0{ }^{\circ} \mathrm{C}$ in the Islands, Central, Lake and Western Highlands Zones (Figure 4c). The $P W$ during the MAM rainfall season is higher in the eastern zones as it was for the JFM and FMA, in the Island Zone $(P W=50$ $\mathrm{mm})$, in the Southern coast zone $(P W=45$ $\mathrm{mm})$ and in the Northern coast zone $(P W=43$ $\mathrm{mm}$ ) (Figure $4 \mathrm{~d}$ ). The $L i$ showed a stable atmosphere over the Southern coast and Northern coast zones (Figure 4d). Hence, the atmosphere during the MAM season is observed to be weakly convective over the Islands, Western Highlands, Central and Lake Zone where the $\mathrm{Li}<0{ }^{\circ} \mathrm{C}$. 


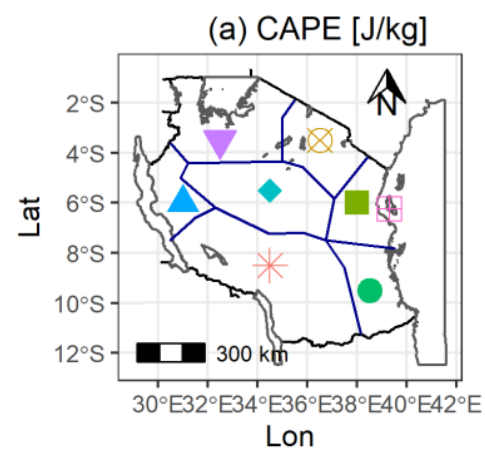

(c) Li [deg C]

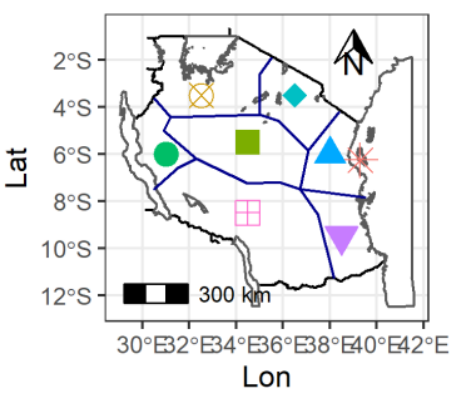

CAPE

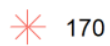

\& 392

412

487

- 603

- 688

788 921

$\mathrm{Li}$

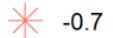

\& -0.46

$-0.26$

$-0.13$

0.26

$\triangle \quad 0.45$

0.58

1.03

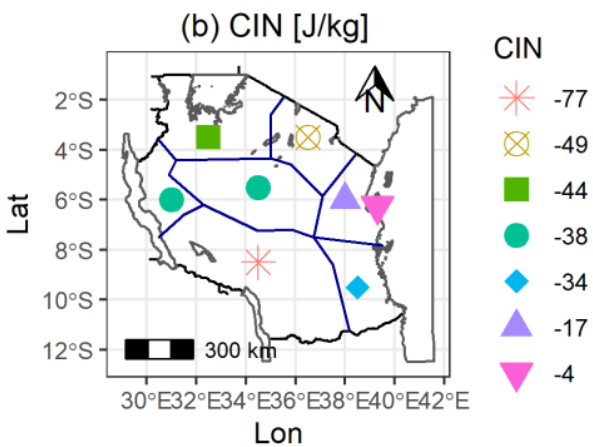

(d) PW [mm]

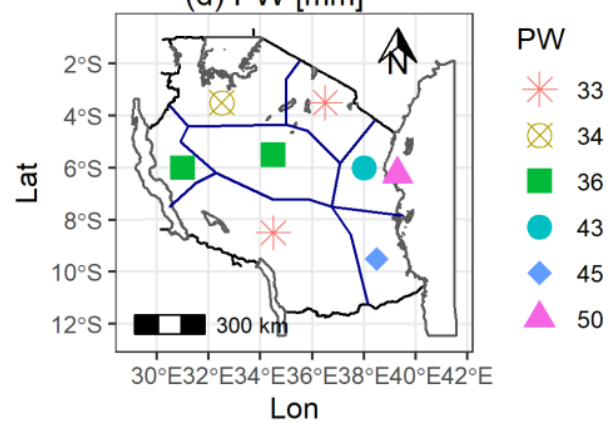

Figure 4: Average variations of the instability parameters during the MAM season in Tanzania.

The average variations of the atmospheric instability parameters during the OND rainfall season are shown in Figure 5. CAPE is observed to have relatively higher values in the Lake Zone $(C A P E=853 \mathrm{~J} / \mathrm{kg})$, Western Highlands zone $(C A P E=789 \mathrm{~J} / \mathrm{kg})$ and in the Central Zone $(C A P E=635 \mathrm{~J} / \mathrm{kg}$ ) (Figure 5a); these zones also have negative lifted index ( $\mathrm{Li}$ ) (Figure 5c) which indicates marginally unstable atmosphere, The $L i$ is positive in the Northern coast, Southern coast, Southern Highlands and in the North Eastern Highlands Zones (Figure 5c), indicating a stable atmosphere over these zones. The $C I N$ values (Figure 5b) ranged from $-3 \mathrm{~J} / \mathrm{kg}$ (low inhibition) in the Islands zone to $-120 \mathrm{~J} / \mathrm{kg}$ (moderate inhibition) in the Southern
Highlands Zone. The precipitable water $(P W)$ (Figure 5d) during the OND season is higher in the eastern zones (Islands, Northern coast, and the Southern coast) and lower to the western zones, it maintains the east-west gradient distribution. The Southern Highlands Zone has the lowest $P W(30 \mathrm{~mm})$ (Figure 5d) followed by Northeastern Highlands Zone with a value of $31 \mathrm{~mm}$ (Figure 5d). The higher $P W$ over the Islands Zone enhanced convection in the atmosphere. Hence, the atmosphere during the OND season, as it was observed for the MAM season, is less convective as compared to JFM and FMA seasons. 


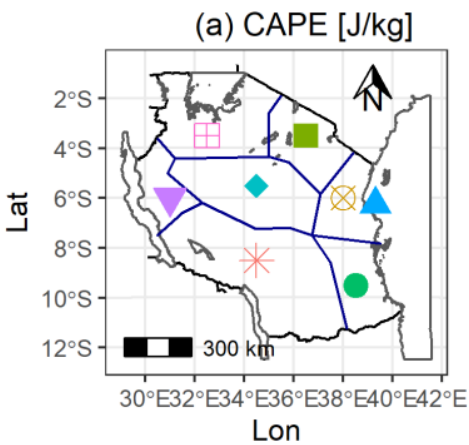

(c) Li [deg C]

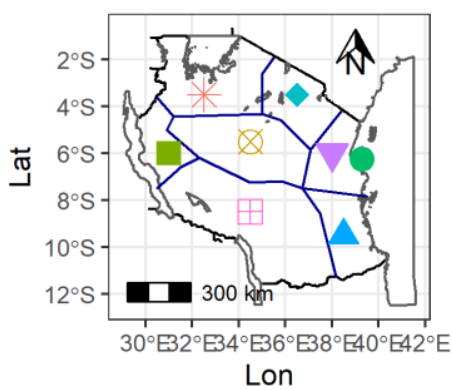

CAPE

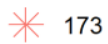

\& 354

381

461

> 635

755

789

853

Li

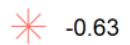

$\otimes \quad-0.42$

$-0.37$

- -0.2

> 0.26

A 0.6

$\checkmark .76$

0.93

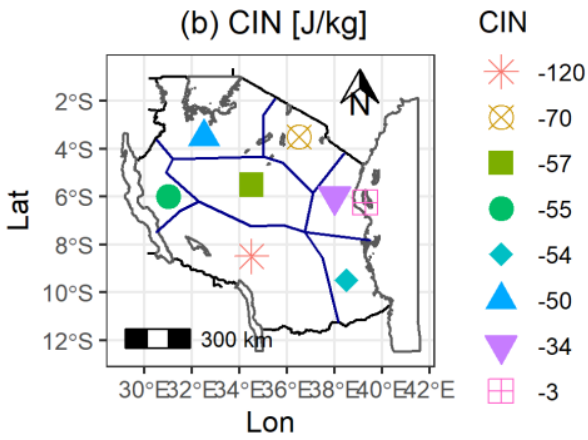

(d) PW [mm]

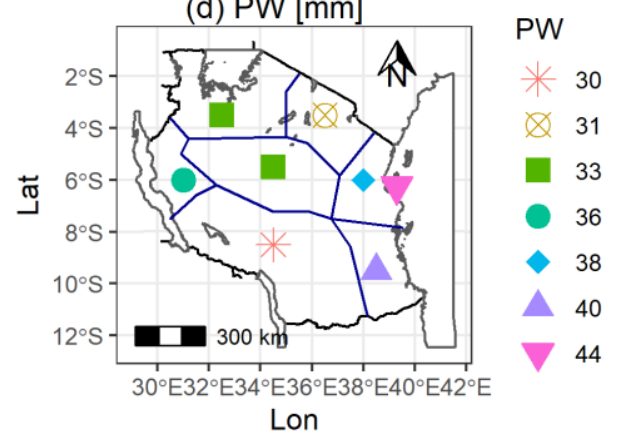

Figure 5: Average variations of the instability parameters during the OND rainfall season in Tanzania.

\section{Discussion}

The atmospheric instability conditions over Tanzania during JFM, FMA, MAM and OND seasons were determined based on the distribution of convective available potential energy (CAPE), convective inhibition $(C I N)$, lifted index $(\mathrm{Li})$ and precipitable water $(P W)$. Results showed that during JFM and FMA rainfall seasons the atmosphere is more convective than during the MAM and OND seasons. CAPE during JFM season ranged from about $793 \mathrm{~J} / \mathrm{kg}$ to $1183 \mathrm{~J} / \mathrm{kg}$ with $C A P E$ $>1000 \mathrm{~J} / \mathrm{kg}$ over the Island Zone, South Coast Zone, Western Highlands Zone, and over the Lake Zone; this means the atmospheric instability conditions were moderately unstable over the mentioned zones. The lifted index during the JFM season was negative over all zones, but it was more negative $(\mathrm{Li}<$ $-1.0{ }^{\circ} \mathrm{C}$ ) over the zones with $C A P E>1000$ $\mathrm{J} / \mathrm{kg}$, implying a more unstable atmosphere than where $\mathrm{Li} \geq-1.0{ }^{\circ} \mathrm{C}$. During JFM, CIN had a range from about $-15 \mathrm{~J} / \mathrm{kg}$ to $-52 \mathrm{~J} / \mathrm{kg}$ which is low inhibition permitting development of convective elements in the atmosphere. The precipitable water $(P W)$ during the JFM ranged from $32 \mathrm{~mm}$ to 49 $\mathrm{mm}$, with higher values of $42 \mathrm{~mm}$ to $49 \mathrm{~mm}$ over the Island, North coast, and Southern coast zones. The lowest value of $P W$ was observed over the Northeastern Highlands Zone $(32 \mathrm{~mm}) . P W$ during the JFM had EastWest gradient, higher values in the eastern zones adjacent to the Indian Ocean and lower values over the western zones. The observed higher $P W$ over the eastern zones is due to the moisture supply from the Indian Ocean, because one of the sources of $P W$ is the evaporation from the water bodies (Ryu et al. 2015, Namaoui et al. 2017), the rate of evaporation might be higher at this time because it is summer. The moisture due to evaporation from the ocean is transported over land by sea-land breeze due to diurnal heating (Jiang 2012). During FMA season, CAPE ranged from about $700 \mathrm{~J} / \mathrm{kg}$ to 1080 $\mathrm{J} / \mathrm{kg}$, whereby a range from $1043 \mathrm{~J} / \mathrm{kg}$ to 1080 $\mathrm{J} / \mathrm{kg}$ was observed over the Islands, Lake and Western Highlands Zones. 
Although the atmosphere was convective all over Tanzania during the JFM and FMA seasons, it was more convective over the Islands, Lake and Western Highlands Zones. For the case of the Islands Zone, which comprises of the Islands of Unguja and Pemba, the atmosphere is more convective due to the diurnal differential heating which leads to land-ocean breeze (LOB) because of land-ocean temperature contrast (Jiang 2012, Yamanaka et al. 2018), The ingredients of LOB are the surface winds and the low-level vertical motion, the former is responsible for the LOB circulations and the later is responsible for the LOB-based convection (Jiang 2012). The low-level moisture over the Island when accompanied by weak surface winds leads longer residence time of such winds over the heated island leading to enhanced moist instability growth (Robinson et al. 2011), hence more convection. The JFM and FMA are seasons with high surface air temperature which enhances the land-ocean temperature contrast. For the Lake and Western Highlands Zones, the atmosphere is more convective due to being in the proximity to the Lake Victoria and Lake Tanganyika, respectively, whereby the lake-land breeze induced circulation plays a major role in the overall organization of convection (Woodhams et al. 2019). The CIN during FMA ranged from $-7 \mathrm{~J} / \mathrm{kg}$ to $-48 \mathrm{~J} / \mathrm{kg}$ which is low inhibition. The lifted index during FMA was negative $\left(\mathrm{Li}<0{ }^{\circ} \mathrm{C}\right)$ all over Tanzania with more negative $\left(\mathrm{Li}<-1^{\circ} \mathrm{C}\right)$ over the Lake and Western Highlands Zones, which indicates more unstable atmosphere and hence more likely to develop convective cells. The $P W$ ranged from $33 \mathrm{~mm}$ to $48 \mathrm{~mm}$; Northeastern Highlands had lowest value of $33 \mathrm{~mm}$, while the Islands, Northern coast and Southern coast had higher $P W$ values from 43 $\mathrm{mm}$ to $48 \mathrm{~mm}$, the east-west gradient distribution of $P W$ was again observed during FMA.

During MAM and OND seasons (Figures 4 and 5), the atmosphere was characterized by low values of $C A P E$ and relatively high values of $C I N$ meaning that it is less convective or more stable than during the JFM and FMA seasons. The CAPE during
MAM ranged from $170 \mathrm{~J} / \mathrm{kg}$ to $921 \mathrm{~J} / \mathrm{kg}$ less than $1000 \mathrm{~J} / \mathrm{kg}$ (Figure 4a) and during OND ranged from $173 \mathrm{~J} / \mathrm{kg}$ to $833 \mathrm{~J} / \mathrm{kg}$ less than $1000 \mathrm{~J} / \mathrm{kg}$ (Figure 5a). The highest value of CAPE during OND (Figure 5a) is lower than the upper value during JFM (Figure 2a) and FMA (Figure 3a) seasons. The CAPE (Figure 5a) distribution in OND has almost the same pattern as that of during the MAM season (Figure 4a). The $C I N$ during MAM (Figure 4b) ranged from $-4 \mathrm{~J} / \mathrm{kg}$ to $-77 \mathrm{~J} / \mathrm{kg}$ and from $3 \mathrm{~J} / \mathrm{kg}$ to $-120 \mathrm{~J} / \mathrm{kg}$ during OND (Figure $5 \mathrm{~b}$ ), with moderate inhibition $(200>|C I N|>50$ $\mathrm{J} / \mathrm{kg}$ ) or $-50 \mathrm{~J} / \mathrm{kg}>C I N>-200 \mathrm{~J} / \mathrm{kg}$ over the Southern Highlands and Northeastern Highlands Zones and low (weak) inhibition $(|C I N|<50 \mathrm{~J} / \mathrm{kg}$ ) or $C I N>-50 \mathrm{~J} / \mathrm{kg}$ over the remaining zones. During MAM, the lifted index $(\mathrm{Li})$ (Figure 4c) was negative only over the Island, Lake, Western Highlands, and Central Zones indicating unstable atmosphere and likely to be convective over these zones which also had high CAPE (Figure 4a) and low $C I N(|C I N|<50 \mathrm{~J} / \mathrm{kg}$ ) (Figure $4 \mathrm{~b}$ ). $P W$ ranged from $33 \mathrm{~mm}$ to $50 \mathrm{~mm}$ during MAM (Figure $4 \mathrm{~d}$ ) with higher $P W$ in the Island (50 $\mathrm{mm})$, Northern coast $(43 \mathrm{~mm})$ and Sothern coast $(45 \mathrm{~mm})$ (Figure $4 \mathrm{~d}$ ), which again shows east-west distribution gradient of $P W$. During OND, $P W$ ranged from $30 \mathrm{~mm}$ to 44 $\mathrm{mm}$ (Figure $5 \mathrm{~d}$ ) with higher values to the eastern zones. The lifted index (Figure 5c) was negative only over Lake, Western Highlands, Island, and Central Zones as it was during MAM.

The lowest CAPE during JFM and FMA on average is about $753 \mathrm{~J} / \mathrm{kg}$ (Figures $2 \mathrm{a}$ and $3 \mathrm{a})$ and the corresponding $C I N$ on average is about $-50 \mathrm{~J} / \mathrm{kg}$ in the range $C I N>-50 \mathrm{~J} / \mathrm{kg}$ (Figures $2 b$ and $3 b$ ) which is the marginal value of weak or low inhibition (Rasmussen et al. 2020). The lowest CAPE during MAM and OND on average is about $170 \mathrm{~J} / \mathrm{kg}$ (Figures $4 \mathrm{a}$ and $5 \mathrm{a}$ ) and the corresponding $C I N$ (Figures $4 \mathrm{~b}$ and $5 \mathrm{~b}$ ) on average is about $99 \mathrm{~J} / \mathrm{kg}$ in the range $(200>|C I N|>50 \mathrm{~J} / \mathrm{kg})$ or $-50 \mathrm{~J} / \mathrm{kg}>C I N>-200 \mathrm{~J} / \mathrm{kg}$ which is moderate inhibition (Rasmussen et al. 2020). This means that in general the atmosphere over Tanzania was moderately unstable during JFM and FMA but weakly unstable 
during the MAM and OND. Hence, the atmosphere is likely to be more convective during JFM and FMA than during the MAM and OND seasons. The results of the present study save as a starting point in understanding seasonal rainfall predictability in Tanzania because the variations and distribution of the instability parameters during JFM, FMA, MAM and OND resemble the variations and distribution of rainfall predictability as observed by Mwinuka et al. (2021).

It is observed in this study that higher $C A P E$ values correspond to $L i<0$ and lower $C A P E$ values correspond to $L i>0$ (Figures $4 \mathrm{a}, 4 \mathrm{c}, 5 \mathrm{a}$ and $5 \mathrm{c}$ ). There is no agreed value of low or high CAPE (Dorrestijn and Crommelin 2015), there are variations from one region to another. The atmosphere is likely to develop convective storms with dynamic forcing in place whenever $C A P E$ gets higher. In general, the atmosphere becomes unstable whenever $C A P E$ is greater than zero, and more unstable for $C A P E$ greater than $1000 \mathrm{~J} / \mathrm{kg}$ (da Silva et al. 2020). In Europe, after observing the records, it was concluded that the probability of the occurrence of lightning was highest for $C A P E>400 \mathrm{~J} / \mathrm{kg}$ and $C I N \geq-50 \mathrm{~J} / \mathrm{kg}$ (Westermayer et al. 2017). In a series of experiments with an environment with given $C A P E$ values, it was found that at $C A P E$ of $450 \mathrm{~J} / \mathrm{kg}$, it was not easy to get a strong storm (Kirkpatrick et al. 2011). In the present study, observations from Figures 4a, 4c, 5a and 5c suggest that there is a critical value of CAPE below which the lifted index is only positive (stable atmosphere), that value of CAPE is approximately $500 \mathrm{~J} / \mathrm{kg}$. Below CAPE $500 \mathrm{~J} / \mathrm{kg}$, the $L i>0$ indicating a stable atmosphere, whereby the temperature of the rising air parcel is lower than that of the environment (da Silva et al. 2020).

No strong CIN (CIN < -200 J/kg) or $(|C I N|>200 \mathrm{~J} / \mathrm{kg}$ ) is observed in either season, but the relatively high CIN (moderate inhibition) observed during OND, and MAM (Figures $4 \mathrm{~b}$ and $5 \mathrm{~b}$ ) has a potential to lead to the building up to higher $C A P E$ values, such that under extra lifting and high surface heating could result into strong convection (Parker 2002). Such higher CAPE can easily break the capping inversion if any to allow thunderstorms to develop in all rainy seasons, but the probability is relatively high during JFM and FMA seasons in which $L i<0$ in all zones (Figures 2c and 3c). During JFM, the lowest value of $C A P E=793>500 \mathrm{~J} / \mathrm{kg}$ and in FMA the lowest value was $C A P E=713>$ $500 \mathrm{~J} / \mathrm{kg}$. During MAM, the lowest $C A P E=$ $170<500 \mathrm{~J} / \mathrm{kg}$ and in OND season, the lowest $C A P E=173<500 \mathrm{~J} / \mathrm{kg}$. During both MAM and OND, CAPE $\geq 500 \mathrm{~J} / \mathrm{kg}$ in the Lake Zone, Western Highlands Zone, Island Zone and over the Central Zone.

It is observed from Figures 2a, 3a, 4a and 5a that CAPE was generally high in the western part specifically in the Lake Zone and Western Highlands Zone, and in the Central Zone. CAPE was also high in the Islands zone. High CAPE is an indication of the presence of conditional unstable lapse rate overlapped with low level moisture in the lower middle troposphere (Doswell and Schultz 2006), this is because CAPE indicates the regions where moisture and conditional instability have overlapped or superimposed on each other (Doswell and Schultz 2006). On the other hand, CAPE was relatively low in the eastern part of Tanzania mainland, specifically in the Northern Coast Zone, the Northeastern Highlands Zone and the Southerrn coast.

In this study, only four instability parameters were considered which are CAPE, $C I N, L i$ and $P W$. In future work, it is important to also determine the atmospheric instability conditions during the rainy seasons by analyzing other instability parameters such as the vertical velocity, moist static energy, vertical wind shear and $L C L$ crossing. Also, the contribution of the atmospheric instability parameters to the seasonal rainfall predictability should be considered in future research. This will reveal what percentage of the seasonal rainfall is contributed by atmospheric convective instability.

In the calculation of CAPE and CIN in this paper, a surface-based air parcel was used with the assumption that the parcel originates near the surface. This assumption is not always satisfying since convection may sometimes occur above the low-level inversion. Future works might find it useful to 
consider using the mixed layer parcels in the calculation of $C A P E$ or $C I N$ which has no assumption of the origin of the air parcel to lift.

\section{Conclusions}

The atmospheric instability conditions during rainy seasons in Tanzania were determined by the analyses of CAPE, CIN, $P W$ and $L i$. It has been found that during JFM and FMA, the atmosphere is moderately unstable with high CAPE and low CIN favouring the development of convective processes. During MAM and OND, the atmosphere was found to be weakly unstable. As the results of the present work have showed, the atmosphere is moderately unstable during JFM and FMA, and hence more likely convective than it is during MAM and OND. The variations and distribution of the instability parameters presented in this paper have patterns which resemble the rainfall predictability patterns as observed by Mwinuka et al. (2021). This observation indicates that there is a connection between the distribution and variations of the atmospheric instability parameters and the seasonal rainfall predictability in Tanzania. Further research is recommended to investigate the contribution of convective instability conditions to the rainfall predictability and distribution in Tanzania. The results of such research will either confirm or reject the hypothesis that seasonal rainfall predictability distribution as observed by Mwinuka et al. (2021) follows the distribution and variations of the atmospheric instability parameters considered in this study. Since only four instability parameters were considered in this study, more parameters need to be analyzed in future research, such as vertical velocity and vertical wind shear.

The seasonal CAPE, CIN, PW and $L i$ presented in this study are the seasonal mean values calculated from the zone area average monthly data. Hourly or daily calculation of CAPE over different spatial points within each zone is recommended, since the state of the atmosphere is subject to change within an hour, or a day and it has been observed elsewhere that the probabilities of convective storms were higher on days with higher CAPE (Huryn et al. 2020).

In the calculation of CAPE and CIN in this paper, a surface-based air parcel was used with the assumption that the parcel originates near the surface. This assumption is not always satisfying since convection may sometimes occur above the low-level inversion. Future works might find it useful to consider using the mixed layer parcels in the calculation of $C A P E$ or $C I N$ which has no assumption of the origin of the air parcel to lift.

\section{Acknowledgement}

The authors wish to thank the ERA5 CDS data service of the ECMWF for providing temperature, surface pressure and dewpoint temperature, geopotential, and upper air relative humidity data. PJ Mwinuka acknowledges the financial support from the Ministry of Education, Science and Technology, United republic of Tanzania.

\section{References}

Ajilesh P, Rakesh V, Sahoo SK and Himesh S 2020 Observed and model-simulated thermodynamic processes associated with urban heavy rainfall events over Bangalore, India. Meteorol. Appl. 27(1): e1854.

Berberan-Santos MN, Bodunov EN and Pogliani L 1997 On the barometric formula. Am. J. Phys. 65: 404-412.

da Silva FP, Rotunno Filho OC, Justi da Silva MGA, Sampaio RJ, Pires GD and de Araújo AAM 2020 Observed and estimated atmospheric thermodynamic instability using radiosonde observations over the city of Rio de Janeiro, Brazil. Meteorol. Atmos. Phys. 132: 297-314.

Davies L, Jakob C, May P, Kumar VV, and Xie S 2013 Relationships between the large-scale atmosphere and the small-scale convective state for Darwin, Australia. $J$. Geophys. Res. Atmos. 118(20): 1153411545.

DeRubertis D 2006 Recent trends in four common stability indices derived from 
U.S. radiosonde observations. J. Climate 19(3): 309-323.

Dorrestijn J, Crommelin DT, Siebesma AP, Jonker HJJ and Jakob C 2015 Stochastic parameterization of convective area fractions with a multicloud model inferred from observational data. J. Atmos. Sci. 72(2): 854-869.

Doswell III C and Schultz D 2006 On the use of indices and parameters in forecasting severe storms. Electr. J. Severe Storms Meteor. 1 (3): 1-22.

Hersbach H, Bell B, Berrisford, P, Hirahara S, Horányi A, Muñoz-Sabater J, Nicolas J, Peubey C, Radu R, Schepers D and Simmons A 2020 The ERA5 global reanalysis. Q. J. Royal Meteorol Soc. 146: 1999-2049.

Holley DM, Dorling SR, Steele CJ and Earl N 2014 A climatology of convective available potential energy in Great Britain. Int. J. Climatol. 34: 3811-3824.

Huryn SM, Mohsin T, Gough WA and Butler K 2020 Determining future thunderstormprone environments in Southern Ontario by using statistical downscaling to project changes in convective available potential energy (CAPE). Theor. Appl. Climatol. 141: 1235-1249.

Jiang Q 2012 A linear theory of threedimensional land-sea breezes J. Atmos. Sci. 69(6): 1890-1909.

Keil C, Heinlein F and Craig GC 2014 The convective adjustment timescale as indicator of predictability of convective precipitation. Quart. J. Royal Meteorol. Soc. 140: 480-490.

Kirkpatrick C, Mccaul EW JR and Cohen C 2011 Sensitivities of simulated convective storms to environmental CAPE. Mon. Weather Rev. 139(11): 3514-3532.

Lepore C, Veneziano D and Molini A 2015 Temperature and CAPE dependence of rainfall extremes in the eastern United States. Geophys. Res. Lett. 42: 74- 83.

Liu C, Zheng N, Zhang K and Liu J 2019 A new method for refining the GNSSderived precipitable water vapor map. Sensors 19(3): 698.

Liu Z, Wong MS, Nichol J and Chan PW 2013 A multi-sensor study of water vapor from radiosonde, MODIS and AERONET: a case study of Hong Kong. Int. J. Climatol. 33: 109-120.

Matthew OJ, Abiye OE and Ayoola MA 2021 Assessment of static stability indices and related thermodynamic parameters for predictions of atmospheric convective potential and precipitation over Nigeria. Meteorol. Atmos. Phys. 133: 675-691.

Mwinuka PJ, Uiso CBS, Chang'a LB and Kumwenda MJ 2021 Monthly and seasonal rainfall concentrations and predictability in Tanzania. Tanz. J. Sci. 47: 243-257.

Myoung B, and Nielsen-Gammon JW 2010 Sensitivity of monthly convective precipitation to environmental conditions. J. Climate 23(1): 166-188.

Namaoui H, Kahlouche S, Belbachir AH, Malderen VR, Brenot $\mathrm{H}$, and Pottiaux E 2017 GPS water vapor and its comparison with radiosonde and ERA-Interim data in Algeria. Adv. Atmos. Sci. 34: 623-634.

Nieto R, Gimeno L, Drumond A, Hernandez E 2010 Lagrangian identification of the main moisture sources and sinks affecting the Mediterranean area. W. Trans. Environ. Dev. 6: 365-374.

Parker DJ 2002 The response of CAPE and CIN to tropospheric thermal variations. Quart. J. R. Meteorol. Soc. 128: 119-130.

R Core Team 2020 R: A language and environment for statistical computing. $\mathrm{R}$ Foundation for Statistical Computing, Vienna, Austria.

Rasmussen KL, Prein AF, Rasmussen RM, Ikeda K and Liu C 2020 Changes in the convective population and thermodynamic environments in convection-permitting regional climate simulations over the United States. Clim. Dyn. 55: 383-408.

Robinson FJ, Sherwood SC, Gerstle D, Liu C, and Kirshbaum DJ 2011 Exploring the Land-ocean contrast in convective vigor using islands. J. Atmos. Sci. 68(3): 602618.

Ryu Y, Smith JA, and Bou-Zeid E 2015 On the climatology of precipitable water and water vapor flux in the mid-Atlantic region of the United States. $J$. Hydrometeorol. 16(1):70-87. 
Sáenz J, González-Rojí SJ, CarrenoMadinabeitia S and Ibarra-Berastegi $G$ 2018 Analysis of atmospheric thermodynamics using the $\mathrm{R}$ package aiRthermo. Comput. Geosci. 122: 113119.

Sui C, Li X and Yang M 2007 On the definition of precipitation efficiency. $J$. Atmos. Sci. 64(12): 4506-4513.

Trenberth KE, Dai A, Rasmussen RM and Parsons DB 2003 The changing character of precipitation. Bull. Am. Meteor. Soc. 84(9): 1205-1218.

Trier Sb, Chen F and Manning KW 2004 A study of convection initiation in a mesoscale model using high-resolution land surface initial conditions. Mon. Weather Rev. 132(12): 2954-2976.

Westermayer AT, Groenemeijer P, Pistotnik G, Sausen R and Faust E 2017 Identification of favorable environments for thunderstorms in reanalysis data. Meteorol. Z. 26(1): 59-70.
Woodhams BJ, Birch CE, Marsham JH, Lane TP, Bain CL, and Webster S 2019 Identifying key controls on storm formation over the Lake Victoria basin. Mon. Weather Rev. 147(9): 3365-3390.

Yamanaka MD, Ogino SY, Wu PM, Hamada JI, Mori S, Matsumoto J and Syamsudin F 2018 Maritime continent coastlines controlling Earth's climate. Prog. Earth Planet. Sci. 5(21).

Yin J, Albertson JD, Rigby JR, and Porporato A 2015 Land and atmospheric controls on initiation and intensity of moist convection: CAPE dynamics and LCL crossings. Water Resour. Res. 51: 84768493.

Zhao Y, Chen D, Li J, Chen D, Chang Y, Li J and Qin R 2020 Enhancement of the summer extreme precipitation over North China by interactions between moisture convergence and topographic settings. Clim. Dyn. 54: 2713-2730. 